\title{
Stable Carbenes: From 'Laboratory Curiosities' to Catalysis Mainstays
}

Tomislav Rovis, ${ }^{\text {a }}$ Steven P. Nolan*b

a Department of Chemistry, Colorado State University, Fort Collins, CO 80523, USA

E-mail: rovis@lamar.colostate.edu

b EaStCHEM School of Chemistry, University of St Andrews, St Andrews, KY16 9ST, UK

E-mail: snolan@st-andrews.ac.uk

Received: 25.05.2013; Accepted: 26.05.2013

\begin{abstract}
The past 20 years have witnessed an explosion in research in the area of stable carbenes. From laboratory curiosities, they have emerged as a front-line alternative to phosphines in metal catalysis. The range of reactivity that they enable in organocatalysis, much of it through their capability to render functional groups umpolung, is enviable. Of course, their unique properties enable them to outperform both phosphines and more traditional Lewis bases in specific transformations. This Cluster assembles leaders in the field that provide a brief introduction to the unique chemistry afforded by these species.
\end{abstract}

Key words: N-heterocyclic carbenes, organocatalysis, ligands on metal, asymmetric transformation

They have been coined 'tertiary phosphine mimics' and 'laboratory curiosities' but the N-heterocyclic carbenes have evolved from these early monikers to now hold a well-deserved place in the synthetic chemist's arsenal. They are 'the best donor phosphines' and this unique property has allowed novel transformations in homogeneous catalysis, namely in olefin metathesis, palladium cross-couplings and most recently in gold-mediated transformations. Their bulk and electronic properties has permitted the design and synthesis of highly thermally stable transition-metal complexes and homogeneous catalysts. Their use in organocatalysis has permitted great advances in the area.

Although one can point to the seminal work of Bertrand ${ }^{1}$ and Arduengo ${ }^{2}$ as the beginnings of stable carbene chemistry, the use of carbenes as both ligands on transition metals and as organocatalysts predates both of these landmark papers. Thiamine-based catalysis of the benzoin reaction is $\sim 70$ years old, ${ }^{3}$ with efforts at asymmetric induction using chiral carbene catalysts dating to Sheehan's work in the $1960 \mathrm{~s} .{ }^{4}$ On the metal-coordination side, Wanzlick and others had used carbenes as ligands. ${ }^{5}$ Nevertheless, there has been an explosion in both of these areas post-1990 and a renewal of interest in the field can be credited to Bertrand's and Arduengo's work.

The past 20 years have seen fantastic advances made in these fields. Carbenes as modifying ligands on metals have become commonplace with the so-called IMes ligand as an alternative to triphenylphosphine or tricyclo-

SYNLETT 2013, 24, 1188-1189

Advanced online publication: 05.06 .2013

DOI: 10.1055/s-0033-1339192; Art ID: ST-2013-R2000-C

(C) Georg Thieme Verlag Stuttgart · New York hexylphosphine. Naturally, this is due to the success such ligands have had in the early days, with olefin metathesis ${ }^{6}$ and palladium cross-coupling catalysis ${ }^{7}$ as prime examples of their potential (Figure 1). Recent years have seen further developments including the use of novel chiral imidazolinylidine carbenes for asymmetric transformations.

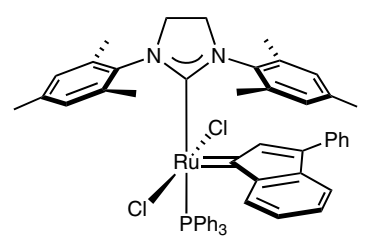

$\mathrm{M}_{20}$

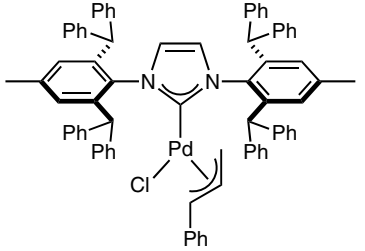

$\left[\mathrm{Pd}\left(\mathrm{IPr}^{*}\right)(\mathrm{cin}) \mathrm{Cl}\right]$ (cin: cinnamyl)
Figure 1 Commercially available ruthenium- and palladium-NHC complexes

Carbenes as organic catalysts have also seen increased popularity. From catalysis of the benzoin ${ }^{8}$ and Stetter ${ }^{9}$ reactions, they have also been shown to catalyze transesterification ${ }^{10}$ as well as redox-based pathways ${ }^{11}$ reminiscent of the Wallach reaction. ${ }^{12}$ Within asymmetric organocatalysis involving carbenes, the triazolinylidine carbenes first introduced by Enders and Teles ${ }^{13}$ with the amino-indanol-derived scaffold developed by Rovis ${ }^{9}$ are dominant (Figure 2).<smiles></smiles>

Figure 2 Triazolinylidine carbenes

The field is still very clearly developing. New reactions catalyzed and controlled by the carbenes as organocatalysts or as ligands continue to appear. Strong contributions continue to emerge from laboratories worldwide and the frontiers are constantly pushed.

In assembling this Cluster of contributions spanning these and many other aspects of carbene chemistry, it was our hope to highlight the vibrant nature of the area and to encourage the community to explore yet undiscovered transformations, whether organometallic or organic, making use of these 'lab curiosities'. 


\section{References}

(1) Igau, A.; Grutzmacher, H.; Baceiredo, A.; Trinquier, G.; Betrand, G. Angew. Chem. Int. Ed. 1989, 28, 621.

(2) Arduengo, A. J. III; Harlow, R. L.; Kline, M. J. Am. Chem. Soc. 1991, 113, 361.

(3) (a) Ugai, T.; Dokawa, T.; Tsubokawa, S. J. Pharm. Soc. Jpn. 1943, 63, 269. (b) Breslow, R. J. Am. Chem. Soc. 1958, 80, 3719.

(4) Sheehan, J. C.; Hunnemann, D. H. J. Am. Chem. Soc 1966, $88,3666$.

(5) (a) Wanzlick, H.-W. Angew. Chem., Int. Ed. Engl. 1962, 1, 75. (b) For a review of these ligands as phosphine mimics, see: Lappert, M. F. J. Organomet. Chem. 1988, 358, 185.

(6) Huang, J.; Stevens, E. D.; Petersen, J. L.; Nolan, S. P. J. Am. Chem. Soc. 1999, 121, 2674.

(7) (a) Zhang, C.; Huang, J.; Trudell, M. L.; Nolan, S. P. J. Org. Chem. 1999, 64, 3804. (b) For well-defined Pd complexes, see: Viciu, M. S.; Germaneau, R. F.; Nolan, S. P. Org. Lett.
2002, 4, 4053. (c) Marion, N.; Navarro, O.; Mei, J.; Stevens, E. D.; Scott, N. M.; Nolan, S. P. J. Am. Chem. Soc. 2006, $128,4101$.

(8) Enders, D.; Kallfass, U. Angew. Chem. Int. Ed. 2002, 41, 1743.

(9) Kerr, M. S.; Read de Alaniz, J.; Rovis, T. J. Am. Chem. Soc. 2002, 124, 10298.

(10) (a) Nyce, G. W.; Lamboy, J. A.; Connor, E. F.; Waymouth, R. M.; Hedrick, J. L. Org. Lett. 2002, 4, 3587. (b) Grasa, G. A.; Gueveli, T.; Singh, R.; Nolan, S. P. J. Org. Chem. 2003, 68,2812

(11) (a) Chow, K. Y.-K.; Bode, J. W. J. Am. Chem. Soc. 2004, 126, 8126. (b) Reynolds, N. T.; Read de Alaniz, J.; Rovis, T. J. Am. Chem. Soc. 2004, 126, 9518.

(12) Wallach, O. Dtsch. Chem. Ges. 1873, 6, 114.

(13) Enders, D.; Breuer, K.; Raabe, G.; Runsink, J.; Teles, J. H.; Melder, J.-P.; Ebel, K.; Brode, S. Angew. Chem., Int. Ed. Engl. 1995, 34, 1021. 